\title{
Bridging the Gaps: Science Fiction in Nanotechnology
}

\author{
José López
}

\begin{abstract}
This paper argues that narrative elements from the science fiction (SF) literary genre are used in the discourse of Nanoscience and Technology (NST) to bridge the gap between what is technically possible today and its inflated promises for the future. The argument is illustrated through a detailed discussion of two NST texts. The paper concludes by arguing that the use of $\mathrm{SF}$ narrative techniques poses serious problems to the development of a critical analysis of the ethical and social implications of NST.
\end{abstract}

Keywords: nanoscience and technology, ethical and social implications, science fiction, extrapolation.

\section{Introduction}

In 1997, Francis Collins, the spokesperson for the US Human Genome Project (HGP), claimed that, "the project's Ethical, Legal and Social Implications (ELSI) program [was] unique among technology programs in its mandate to consider and deal with these issues alongside the development of the technology" (cited in McCain 2003, p. 112). Recent assessments of its impact have been far from celebratory (e.g. Evans 2002, Huijer 2003, McCain 2003). Indeed, it is claimed that the ELSI program insulated the HGP from criticism rather than facilitating negotiations between scientists and non-scientists (Huijer 2003, p. 488).

Against this background, when Mihail Roco, a key promoter of nanoscience and technology (NST) ${ }^{2}$ in the U.S. and director of the National Nanotechnology Initiative (NNI), claims that societal implications have been an integral component of the NNI from the start and argues that the National Science Foundation (NSF) "has made support for social, ethical and economic research studies a priority” (Roco 2003a, p. 185), it is reasonable to wonder to what extent this represents a genuine invitation to the agora ${ }^{3}$ or a façade that merely disguises science's traditional agoraphobia. As Nik Brown has recently argued, 'The 'post-normal science' thesis [...] which sees science 
increasingly dependent on wider political and public aspirations should, it appears, be received with caution" (Brown 2003, p. 18). However, notwithstanding these reservations, it would be wrong to dismiss the opportunities created by the current social and political exigencies requiring technoscience to explore the ethical and social implications of its activities. Even if it is just a façade, it represents a surface that at the very least can be tagged with critical graffiti.

Having said this, it would be equally problematic to think that the deliberative space in which discussions of the social and ethical implications of nanotechnology are unfolding, or will unfold, is an empty one. At the moment, this space is being structured by a form of extrapolation that draws on narrative elements from the science fiction (SF) genre. In this paper, I argue that there are important limitations associated with trying to understand the ethical and social implications of NST within this discursive space, and that an understanding of these limitations must precede or should be taken into account in a more reflexive debate on NST.

First, I consider the implications of arguing that SF is not an external but an internal aspect of NST discourse. Following this, I show that the central metaphor in NST discourse - nanotechnoscientists as master builders - provides a semantic link to SF narrative elements. This link allows NST authors to extrapolate by drawing on SF world-building techniques. I, then, provide a detailed analysis of this process by examining the key role that the SF literary device of the novum plays in two NST texts. ${ }^{4}$ A number of scholars have already drawn attention to the important function that the SF literary device of the novum plays in NST discourse, especially Milburn (2002) and Marshall (2004) and to a lesser extent Miksanek (2001) and Landon (2004). What my discussion adds to these is a more detailed textual analysis of the functioning of the novum and an exploration of the implications of these discursive strategies for debates on the ethical and social implications of NST.

The first text is Drexler's Engines of Creation, the second an edited book on the convergence of nano, bio, information technology and cognitive science (NBIC), Converging Technologies for Improving Human Performance. It is edited by Mihail C. Roco and Williams Sims Bainbridge, both active promoters of NST. ${ }^{5}$ Although many in the NST community might argue that Drexler's vision is both dated and outside the mainstream, the editors of and contributors to the second text are very much part of the NST mainstream. In bringing these two texts together, I show that there are more similarities than would be initially expected, not necessarily in terms of their substantive claims but in terms of the formal narrative structures through which their claims are engendered. ${ }^{6}$ This is followed by a discussion of the limitations associated with the framing of ethical and social implications by current NST discourse. In the conclusion, I consider some further implications of the way NST discourse mobilizes the future. 


\section{Science Fiction and Nanoscience and Technology}

Technoscientists in the NST field frequently draw on SF in order to construct a binary opposition that is deployed to police the boundary (Gieryn 1999) between science and non-science. A well-known instance is the debate initiated by Gary Stix (1996), a staff writer for Scientific American, who wrote a highly critical piece on Eric Drexler's agenda for nanotechnology.? Amongst other things, as Milburn notes, Stix compares "Drexler's writing to the scientific romances of Jules Verne and H.G. Wells, suggesting that 'real nanotechnology' is not to be found in these science fiction stories" (Milburn 2002, p. 265). However, as Fogelberg and Glimell argue in their analysis of the debate, one of the key issues at stake is the meaning of scientific practice (Fogelberg \& Glimell 2003, pp. 10-12). Drexler's more speculative extrapolative approach, based on theoretical computational modeling, is seen to be at odds with the experimentally based work that is taken to be the hallmark of good science. ${ }^{8}$

My purpose in examining the relationship between SF and NST is not to explore how SF is invoked to criticize NST for its 'unscientific excesses' or to address the mediating role that $\mathrm{SF}$, as an object external to science, might play between the scientific community and the public at large in popular culture. ${ }^{9}$ Instead, I argue that narrative elements from the SF genre are not external to but contribute to the constitution of NST discourse itself. By drawing attention to the shifting and permeable border between science and SF in NST, it is not my intention to either put in question the scientific credentials of nanotechnoscientists by insinuating that they are not doing 'real science' or, more generally, to undermine the credibility of science due to its reliance on narrative techniques found in fiction. As Donna Haraway argues,

Not only is no language, including mathematics, ever free of troping; not only is facticity always saturated by metaphoricity; but also, any sustained account of the world is dense with storytelling. 'Reality' is not compromised by the pervasiveness of narrative; one gives up nothing except the illusion of epistemological transcendence, by attending closely to stories. [Haraway 1997, p. 64]

Science is not possible despite narrative but precisely because of it. However, not all narratives are the same; they draw on different naratological devices. Discourses that extrapolate technoscientific developments into the future, through SF narrative elements, contain assumptions about, amongst other things, the nature of being, the dynamics of historical change, the aspirations of citizens, and the relationship between society, culture and technoscience. With this in mind, I will now discuss more specifically how SF narrative elements are incorporated into NST.

Definitions of NST are highly contested (Fogelberg \& Glimell 2003, pp. 5-26). This is due to its status as an 'emergent science', that is to say a science 
whose truth claims remain to be settled by scientific or public consensus (Hamilton 2003, p. 268). ${ }^{10}$ What is more, given the heterogeneous and interdisciplinary nature of the NST field, ${ }^{11}$ it is not likely that definitional closure will be achieved soon. Definitional problems also arise because NST, as we shall see below, is radically future oriented; thus, it is also defined by how its potential is refracted towards competing futures (Wood et al. 2003, p. 3).

However, a minimum definition would draw attention to the significance of its length scale:

One nanometer (one billionth of a meter) is a magical point on the dimensional scale. Nanostructures are at the confluence of the smallest of humanmade devices and the largest molecules of living things. Nanoscale science and engineering here refer to the fundamental understanding and resulting technological advances arising from the exploitation of new physical, chemical and biological properties of systems that are intermediate in size, between isolated atoms and molecules and bulk materials, where the transitional properties between the two limits can be controlled. [Roco cited in Ratner \& Ratner 2003, p. 7]

The 'newness' 12 of the nanoscale refers to the difference between the macroscopic and nanoscopic properties of materials. To take Ratner and Ratner's (2003) example, although a metric ton, a kilogram, and gram of gold all have the same physical properties, the same is not true when one scales down to the nano length. Gold's color, melting point, and chemical properties are different at the nano length scale as a result of the nature of atomic interactions and the fact that these are not averaged out as they are in bulk material. In other words, "Nano gold doesn't act like bulk gold" (Ratner \& Ratner 2003, p. 2). Thus as Roco and Bainbridge argue, "The nanoscale is not just another step toward miniaturization, but a qualitatively new scale. The new behavior is dominated by quantum mechanics, material confinement in small structures, large interfaces, and other unique properties" (2001, pp. 4-5). ${ }^{13}$

When these unique properties are combined with the prevalent and dominant metaphor ${ }^{14}$ that reigns in NST discourse - nanostructures as the building blocks of matter and the nanotechnoscientist as the master builder - we can begin to appreciate the radical transformative powers that NST not only denotes but also connotes. ${ }^{15}$ For instance, the Nobel laureate for physics, Horst Stormer, suggests that when we are empowered by nanotechnology to "play with the ultimate toy box of nature - atoms and molecules [...] the possibilities to create new things appear limitless" (cited in NSTC 1999, p. 1). Indeed it is not infrequent to encounter references to NST's radical transformative powers. For instance, claims such as "By anyone's measure, nanotechnology is the next big thing. In fact, according to government R\&D planners, nanotechnology is nothing short of the next Industrial Revolution" (Schulz 2000, p. 41) are rather common. 
In fact, these claims are foundational for analyses of the ethical, legal, and social implications that have been initiated by the NST community itself. ${ }^{16}$ One might even argue that the fact that the social implications have been central to the NNI represents not so much a belief in the legitimacy of submitting NST to social and ethical analysis as much as the conviction that NST is like no other technoscientific practice in its ability to impact and transform both the social and natural world. As Wood et al. argue in their review of the emerging field, "Nanotechnology is being heralded as a new technological revolution, one so profound that it will touch all aspects of human society" (2003, p. 1).

Yet, while it is certainly the case that there have been important developments that make possible the manipulation of matter with precision at the nanoscale, as commentators have also noted, NST is only here as a trace of a future yet to be produced (Fogelberg \& Glimell 2003, Milburn 2002, Wood et al. 2003). Even NST's most energetic promoters have to admit that "nanotechnology is still in its infancy, because only rudimentary nanostructures can be created with some control" (Roco \& Bainbridge 2001, p. 1). There is a rather significant gap between what can be achieved with NST today and what is imagined that will be achievable in the future; predictions of revolutionary transformations seem premature.

This gap, of course, is not specific to NST and can be found in other fields. It is typically sutured rhetorically through hype that not only mobilizes meaning but also social, political, and economic resources by promising breathtaking advances, miracle cures, and virtually unimaginable wealth. ${ }^{17}$ However, in the case of NST the hype is different. For instance, although biotechnology hype promises wealth, global food abundance, and intimations of immortality through genetic therapy and enhancement, NST's hype promises more! By drawing on the metaphor of the nanotechnoscientist as the master builder and NST as the toolbox that makes possible the manipulation of the fundamental stuff that makes up the world, NST claims nothing less than to be able to rebuild the world. This ultimate conceit, which feeds NST's molecular speculations, is elegantly captured by the title of the U.S. National Science and Technology Council brochure on nanotechnology: "Nanotechnology: Shaping the World Atom by Atom" (NSTC 1999).

It is instructive to compare the semantic suppleness associated with the metaphors used in the HGP with those deployed in NST. The HGP promised to produce a "plan", "blueprint", "encyclopaedia”, or a "program" of life (Rothman 1998, p. 25). In all instances its vision of the future was limited by the frontier between the organic and the inorganic. However, NST's 'shapingthe-world-one-atom-at-a-time' metaphor makes it possible to transcend this boundary: Nobel laureate and nanotechnoscientist Richard Smalley claims, "Nanotechnology is the builder's final frontier" (cited in NSTC 1999, p. 1). 
Recognizing the centrality of the world-building metaphor is important because its semantic connotations also make it possible for NST discourse to draw on narrative elements from the SF literary genre that is, in part, characterized by its ability to produce radically different future or parallel worlds. This creates the discursive conditions for what, following Landon, we can call SF thinking. SF thinking

generates the rhetoric that bridges the gap between the givens of science and the goals of the imaginary marvelous, the emphasis always on 'explaining' the marvelous with rhetoric that makes it seem plausible, or at least not yet impossible. [cited in Gerlach \& Hamilton 2000, p. 465]

By incorporating SF thinking, NST discourse overcomes the gap between what is possible today and what might be possible in the future. ${ }^{18}$ This is achieved by using extrapolative narrative techniques that are well established in the genre. In other words, or in other worlds, it is able to solve the tension inherent in claiming that we are already living in a nano-era while also recognizing that the dawning of the nano-era depends on much that has yet to happen.

\section{Mainstream and Periphery in Nanoscience and Technology}

Although Drexler is credited with having coined the term 'nanotechnology', it is undeniable that his status in the field is problematic. As noted above, he is one of the targets of the science fiction/fact opposition deployed to locate certain NST activities outside the boundary of real science. It is frequently argued that his vision of nanotechnology remains peripheral and outside the mainstream. As evidence for this, one might point to the fact that his agenda has certainly not been explicitly endorsed by the NNI. ${ }^{19}$ Still, even though his book, Engines of Creation, may be frequently criticized, it has also introduced a generation of scientists and engineers to a nanotech 'futurescape'. Thus even a staunch critic such as Smalley, ${ }^{20}$ who believes that there are insurmountable objections to Drexler's proposed molecular assemblers, has conceded that Drexler "has had tremendous effect on the field through his books" (cited in Milburn 2002, p. 280). Moreover, the disagreement between Smalley and Drexler is not about the revolutionary or social transformative impact of NST (i.e. its capacity to rebuild the world):

Smalley acknowledges that nanotechnology, even in the more modest form of his own nanotubes of carbon, eventually 'may change the future of humankind' and that nanotechnology from chemistry on a nanometerscale 'may make even Drexler blush'. [Fogelberg \& Glimell 2003, p. 19] 
In making these points, it is not my intention to shore up Drexler's scientific credibility or to undermine those of his opponents. Rather, it is to note that we should not allow the controversies over the viability, or not, of molecular assemblers to obscure the similarities that exist in terms of how SF narrative elements are used to negotiate the gap between current technoscientific capabilities and their future development. ${ }^{21}$

In Engines of Creation, Drexler introduces us to a future where molecular manufacturing will be capable of making

virtually anything from common materials without labor, replacing smoking factories with systems as clean as forests. They will transform technology and the economy at their roots [...] They will indeed be engines of abundance. [Drexler 1990, p. 63]

Engines of health, or cell repair machines, will cure disease and prolong life; other engines will contribute to the launching of a new space program. All of this, and more, will be possible on the journey towards a positive-sum society that will culminate in an "open future of wealth, room and diversity, [where] groups will be free to form almost any sort of society they wish, free to fail or set a shinning example for the world" (Drexler 1990, p. 237). The only problem is that these "engines of creation" or molecular assemblers have yet to be produced. Still, Drexler's writing narrates their coming as unavoidable.

The arrival of assemblers is to follow a path already initiated by current bio and molecular technology. Protein machines will combine the cutting and pasting abilities of enzymes with the programmability of ribosomes to produce new nanoscale non-protein materials that will in turn be used to create second-generation nanomachines or universal assemblers. When these assemblers are combined with the astronomical computing power of nanocomputers, the knowledge of molecular and atomic architecture collated by nanoreverse-engineering-machines or disassemblers, and the ability to self-replicate in order to achieve economies of nanoscale, the nano-era will finally be upon us (Drexler 1990, pp. 3-20). ${ }^{22}$

If we leave aside the technical argument regarding the viability of molecular assemblers, there are a number of narrative devices that make nanomachines both credible and inevitable in Drexler's text. Following SF convention, his text constructs a "sublime chronotope" in which the action unfolds (i.e. the romance of how molecular assemblers will rebuild the world). SF critic Istvan Csicsery-Ronay, Jr. defines the sublime chronotope as a "literary 'space-time' where fictional things work according to their own particular laws of time and space. SF works generally depict one or more special chronotopes that are wonderfully strange and ultimately vast and powerful" (CsicseryRonay 1996, p. 386). ${ }^{23}$ In Drexler's text, the chronotope has two dimensions: synchronic (i.e. at one point in time) and diachronic (i.e. across time or historical). Synchronically, Drexler's nano-chronotope invites us to see a world that 
has been thoroughly overhauled and reconstituted through the tropes of the atomic, the molecular, and the machinic. Diachronically, he narrates an 'engine' of historical change that links the past with a de-familiarized present. This present promises the future, as the acorn promises the oak..$^{24}$

In synchronic mode, the chronotope is woven through the narration of a space that is both familiar and alien. It is our world but its landscapes, scale, structures, rules, and action are all atomic. If Marx claimed that "Value [...] does not have its description branded on its forehead; it rather transforms every product of labor into a social hieroglyphic" (cited in Graham 2002, p. 236), Drexler might argue that value is inscribed as an atomic hieroglyphic. Indeed, he begins his book by claiming that "throughout history, variations in the arrangement of atoms have distinguished the cheap from the cherished, the diseased from the healthy" (Drexler 1990, p. 3), and he goes on to write, "Our ability to arrange atoms lies at the foundation of technology. We have come far in our atom arranging, from chipping flint for arrowheads to machining aluminum for spaceships" (ibid.).

Framed by Drexler's nano-chronotope, human interaction with nature and the development of technology is nothing more than the attempt to manipulate atoms, initially clumsily but increasingly with more precision (i.e. bulk versus molecular technology). The chronotope that stages the plot in Engines of Creation not only invites us to reconsider our relationship vis-à-vis nature, it also demands that we develop a molecular conception of our bodily selves: "The ill, the old and the injured all suffer from misarranged patterns of atoms, whether misarranged by invading viruses, passing time or swerving cars. Devices able to rearrange atoms will be able to set them right" (ibid., p. 99).

The figure of 'the machine' is the second key discursive element in the chronotope. Drexler argues that there is no more incontrovertible evidence of the viability of nanomachines or molecular assemblers than the existence of protein machines or ribosomes that assemble proteins in our cells (ibid., p. 6). Thus, "molecular machines in the cell demonstrate that molecular machines work" (ibid.). A little later in the text, he first redefines life as a "special structure" which is governed by the "machinery of life" (ibid., p. 17) and adds, "The history of life is the history of an arms race based on molecular machinery" (ibid., p. 26).

By combining a world where reality is reduced to myriads of atomic configurations and the bonds that hold or fail to bind them together, where technology is crude or precise atomic manipulation, health a harmonious atomic arrangement and disease an atomic cacophony, with vital molecular machinery as the basis of life, Drexler's text re-ontologizes the world. In doing so, he creates a sublime chronotope that provides an ideal habitat for his nanomachines because they straddle the two significant dimensions of this new domain, i.e. the atomic and the machinic. Grab your atomic force microscopes. We have entered the age of assembler and the book of the world is written in the language of atomic bonds. 


\section{The Breakthrough as the Novum}

The synchronic dimension of the chronotope is traversed by a diachronic or historical vector. It narrates how we have arrived at the stage where the assembler revolution is already contained in our present, making it inevitable. Drexler claims that it is possible to isolate the principles of change whose explanatory domain span "molecules, cells, beasts, minds, and machines [and] should endure even in an age of biotechnology, nanomachines and artificial minds" (ibid., p. 21). After identifying molecular replicators - i.e. RNA, viral genes, human genes, etc. - as the chronotope's principal historical actors (ibid., p. 25), he argues that through the evolutionary mechanisms of mutation and selection there is a continuity between The Rise of the Replicators (RNA molecules) and the rise of all other things that populate the earth:

Mutation and selection of genes has, through long ages, filled the world with grass and trees, with insects, fish and people. More recently other things have appeared and multiplied - tools, houses, aircraft, and computers. And like the lifeless RNA molecules, this hardware has evolved. [Ibid., p. 30]

He further embeds the production of 'hardware' within evolutionary semantics by arguing that the principles of engineering can be understood in terms of mutation and selection: "In engineering, enlightened trial and error, not the planning of flawless intellects, has brought most advances" (ibid., p. 31).

If synchronically we have seen how the atomic and machinic nanochronotope provides an ideal space for molecular assemblers, diachronically the chronotope locates the engineer as the hero whose practice embodies the principles of change that govern the nano-chronotope. Moreover, by inserting the engineer in the context of evolutionary trans-historical forces, the molecular-assembler revolution becomes unstoppable. Thus, it is not surprising that he concludes his book by interrogating the present with questions that originate in the future:

If we succeed (and if you survive) then you may be honored with endless questions from pesky great-grandchildren: 'What was it like when you were a kid, back before the Breakthrough?' and 'What was it like growing old?' and 'What did you think when you heard the Breakthrough was coming?' and 'What did you do then?' By your answers you will tell once more the tale of how the future was won. [Ibid., p. 239]

This is not only a call for 'nano-engineers of the world to unite' and take their place in a world historical event that has already been determined, it also provides the key to the functioning of the chronotope.

What Drexler's text achieves, unwittingly or not, is a narrative that reontologizes the past, present, and future. This is achieved by rebuilding the world synchronically and diachronically around the Breakthrough, the arrival of the molecular assembler. The narrative process whereby a single element is 
used as the axis around which a future alternative world is generated is a key discursive element of SF. Though there is much debate of the status of SF as a genre, there is some consensus on the centrality of the device of the novum:

A novum is a deliberately introduced change made to the world as experienced by author and reader, but a change based on scientific or other logic; it is such a significant part of the SF that the novum frequently determines the subsequent narrative. [James 1994, p. 108, italics added]

The novum is a variation of the "What if..." question that is used as a worldbuilding device by extrapolating the potential ramifications of the interruption to reality contained in the question (e.g. time travel, artificial intelligence, a parallel universe, molecular assembly). The assembled world derives its coherence not from the logic or validity of the novum itself but from the way all its dimensions have been processed by the machinery of the novum. This is precisely the discursive scaffolding that underpins Drexler's sublime chronotope and in turn provides the stage that projects nanotechnology into the future, or retracts the future into the present. In other words, this is how Drexler bridges the gap between what is possible now and what he envisions will be possible in the future. Without this SF discursive device, Drexler's vision of nanotechnology could not be assembled.

\section{NBIC Convergence}

Converging Technologies for Improving Human Performance: Nanotechnology, Biotechnology, Information Technology and Cognitive Science is a published report that derives from a 2001 workshop sponsored by the NSF and the Department of Commerce (DOC). Since then a number of NBIC meetings have taken place. The report is of interest for a variety of reasons. First, it is the most recent and sustained effort to construct a broad vision of NST by making NBIC central to the achievement of a variety of technoscientific, social, economic, and political goals. Moreover, given the scope and transdisciplinary nature of the NNI, and the variety of agencies that it mobilized, a broad integrative vision is likely to remain a crucial element in future national NST initiatives. ${ }^{25}$ Second, the editors and contributors are drawn from NST's mainstream. For Mihail Roco, a key figure in the NNI, NBIC represents a continuation of the work already begun. ${ }^{26}$ Finally, both editors have consistently championed 'analyses of ethical and social implications'; consequently, it provides an ideal site to read the framing of these questions within NST discourse.

NBIC supporters argue that the impetus for convergence is driven by "the integration and synergy of the four technologies (nano-bio-info-cogno) [that] originate from the nanoscale, where the building blocks of matter are estab- 
lished" (Roco \& Bainbridge 2003, p. vii). The integration between bio and nano is possible because the unity of matter at the nanoscale means that the structure of both organic and inorganic materials is determined by the same fundamental principles. Consequently, it becomes possible for technology to "harness natural processes to engineer new materials, biological products, and machines from the nanoscale up to the scale of meters" (ibid., p. 2). The integration and synergies between info nano and bio are diverse. On the one hand, the enhancement of computing power (i.e. speed and memory) is expected to derive from new nano-engineered materials as well as from novel architectures in the form of quantum and biological (DNA based) computing (Theis 2001; Ratner \& Ratner 2003, pp. 130-39; Wood et al. 2003, pp. 19-24). On the other hand, developments in NST and biotechnology themselves depend on computer based modeling and visualization made possible by the digitalization of molecular processes (Johnson 2003, Thacker 2004, Roco 2003b).

The integration of the cognitive science component is tied to the development of the "Human Cognome Project" whose goal would be to map "the structure and function of the mind" (Bainbridge 2003, p. 97). It is argued that cognitive science would be able to explain "the mind and human behavior" by understanding their "physico-chemical- biological processes at the nanoscale" (Roco 2003c, p. 301). This would be made possible by the convergence of bio, computer, and nanotechnology (Roco \& Bainbridge 2003, p. 12). In turn, the ability to enhance cognition and communication, as a result of the accrued knowledge, would make new scientific and technological discoveries possible. Ultimately, the multiple synergistic pathways in NBIC herald a new renaissance

based on a comprehensive understanding of the structure and behavior of matter from the nanoscale up to the most complex systems yet discovered, the human brain. Unification of science based on unity in nature and its holistic investigation will lead to technological convergence and a more efficient social structure for reaching human goals. [Ibid., p. 1]

It is interesting to note that amongst the goals reported in the volume are items that would not be out of place even in Eric Drexler's nano-chronotope. If Drexler entices us with visions of abundance, a contributor to the NBIC volume defines poverty as a technological challenge and predicts that intelligent machines will "eradicate poverty and usher in a golden age for all humankind" (Albus 2003, p. 293). Indeed, such will be the magnitude of the wealth produced that "new economic theories based on abundance may emerge to replace current theories based on scarcity" (ibid., p. 292).

Engines of Creation, as noted above, presents the possibility of harnessing the design principles and mechanisms of biological molecular machines to create nanomachines capable of producing inorganic materials. In similar fashion, Roco and Bainbridge report that "fundamental knowledge about molecularlevel processes essential to the growth and metabolism of living cells may be 
applied, through analogy, to development of new organic materials" (Roco \& Bainbridge 2003, p. 11). If the previous two scenarios are conceivable in a Drexlerian world, the next one, brain-to-brain communication, is nudging towards SF, even by Drexler's standards (Drexler 1990, p. 234). The NBIC program foresees the development of The Communicator, a device that will

enhance individual attributes and remove barriers to group communication such as $[. .$.$] user's physical disabilities, language differences, geographic dis-$ tance and disparity in the knowledge possessed by group members [...] Improving group interactions via brain-to-brain and brain-machine-brain interfaces will also be explored. [Albus et al. 2003, p. 276]

For Roco and Bainbridge, brain-to-brain communication provides a stepping stone towards a networked society capable of sustaining "a global intelligence" (Roco \& Bainbridge 2003, p. 22) where "humanity would become like a single distributed and interconnected 'brain' based on new core pathways of society" (ibid., p. 6). There are more examples that could be cited, but the point is not to isolate individual objects or scenarios that appear to be plucked out of SF novels, but to understand how NST discourse can circulate such inflated future currency as current technoscientific tender.

Not unlike Drexler's book, the NBIC text embeds its promissory notes in a sublime chronotope that re-ontologizes the world both synchronically and diachronically. In synchronic mode, the NBIC-chronotope is constituted as a continuous and unified space-time, which stretches from the nanoscale to the scale of meters and beyond (ibid., p. 2). The coherence of this space is underwritten by the unity of matter at the nanoscale and is thus regulated by a hierarchy of causality that operates from the bottom up (ibid.). The fundamental properties of matter are determined by its constituent molecular dynamics. Phenomena such as memory, emotion, and thought are to be explained by reference to a hierarchy that privileges the nanoscale organization of atoms and constructs a causal explanatory pathway that links nanostructures to the structure of DNA that in turn extends the link to the interaction of neurons in the brain (ibid., p. 13). The great chain of being begins at the bottom but does not end with the body or the brain.

In the NBIC-chronotope, the conceptualization of the brain serves to fuse what would seem to be different phenomenological domains (i.e. the material and the social-cultural), allowing NBIC to expand its ontological prospecting claims. The brain is operationalized as a communicative and information processing system; social interaction and group behavior are defined by the same operators. This opens the way to re-ontologizing the brain's neural network as the cognitive 'nanostructure' of social life through which the bottom-up causal hierarchy can be replicated in the social and cultural domains. Thus, the ability to enhance these functions (i.e. information processing and communication) by drawing on a cognitive science leveraged 
by bio, nano, and information technology makes it possible to conceive of the "improvement of collective behavior and productivity" (Roco 2003b, p. 82). It is in this sense that convergence would lead to devices like the Communicator that would provide the basis for a "more efficient social structure for reaching human goals" (Roco \& Bainbridge 2003, p. 1) and even for envisioning the "bond of humanity driven by an interconnected virtual brain of the Earth's communities searching for intellectual comprehension and conquest of nature" (Roco 2003b, p. 93).

Fuelling this vision of the ability to manage everything from the nanoscale to the interactions of humanity as a whole is an explicit and profound reductionism that arises from the conviction that "all disciplines share a common ability to work at the molecular and nano length scales using information technology and biology concepts" (Roco 2003b, p. 93). As a result, "partisans" who argue for the "independence of biology, psychology, and the social sciences [...] against 'reductionism', asserting that their fields had discovered autonomous truths that should not be reduced" are utterly self-defeating (Roco \& Bainbridge 2003, p. 13). ${ }^{27}$ Underpinning this reductionism is an ontology in which distinct phenomenological domains lack domain-specific principles of organization, thus "a networked society of billions of human beings" is to the human being what "a human being is to a single nerve cell" (ibid., p. 22). Consequently, a "collective social system may be compared to a larger form of a biological organism" (ibid.).

The unification of the natural and social sciences would make possible the development of an explanatory regime capable of encompassing "collective behavior in physics, chemistry, biology, engineering, astronomy, and society" (Roco 2003b, p. 84). Indeed, in a chronotope where every internal ontological border is disassembled to its constituent molecular configurations, it becomes possible to conceive of a "predictive science of society and to apply corrective actions based on the convergence ideas of NBIC", and to re-ontologize culture as the product of the brain's physiology thus leading to the dual evolution of human culture and physiology (Roco \& Bainbridge 2003, p. 22).

Underpinning the NBIC-chronotope are two distinct but interlinked tropes: 'communication' and 'unity'. That the ontologization of DNA as an informational code and the conceptualization of the genome as a biological computer (Thacker 2004, p. 40) makes it possible to think of molecular intervention in terms of reprogramming, is already well established..$^{28}$ By asserting the unity of matter at the nanoscale and erasing the distinction between the organic and inorganic, NST is able to extend the informational paradigm to all matter:

Programmable matter is a technical approach to the physical world in which the distinction between information and materiality is effaced. For nanotech, the entire apparatus of nanomachines [...] is itself built out of the same molecular and atomic elements that compose the physical world. Nanotech's ul- 
timate engineering fantasy - that of the nanocomputer or a computer hardware apparatus that is assembled from atoms - is a direct example of its will to materialize information. [Thacker 2004, p. 138]

NBIC incorporates society and culture into this informational logic by conceptualizing the brain itself as the programmable matter that underpins social behavior and interaction. Thus there is no longer an outside of the NBIC chronotope. The corollary to this unified world is the existence of a common molecular syntax: once deciphered, it will make just about anything possible. It is this universal machine language of matter that allows the conversion between bits, atoms, neurons, and genes and the seamless integration of people, technologies, societies, and humanity.

If synchronically it is the ontological unity of the social and natural world arising from a common molecular grammar that makes NBIC convergence inevitable, diachronically it is the ontologization of the history of humanity as a transhistorical quest for improvements in human performance. This is presented diagrammatically with a table which begins with the development of the cell, body, brain, etc. includes universities, printing, the industrial revolution, etc. and inexorably moves to NBIC in order to predict "societal and business reorganization" and even "evolution transcending human cell, body and brain" (Roco \& Bainbridge 2003, p. 23). This historical trajectory opens up the space for a new type of historical actor, a new renaissance man or woman, the scientist engineer, capable of mastering the unified language of the world, in others words capable of punctuating the current equilibrium by completing a process that has already begun: NBIC convergence.

The sense of inevitability, however, is the product of how the gap between the present and future has been overcome. Like Drexler's text, the NBIC text draws on the narrative device of the novum (i.e. NBIC convergence) that constructs a discursively coherent world that stretches from the past to the future. However, the price of coherence is that everything must be traced back to the interruption that the novum introduces. Thus, all of history converges towards the novum that in turn gives birth to the future. In the narrative developed in the NBIC text, every dimension of the world, both diachronic and synchronic, has been processed through the NBIC filter and colored by the trope of convergence and unity. Thus, the principles governing the structure of organic and inorganic matter converge, the technologies of different disciplines converge, the natural sciences converge, the natural and social sciences converge, individuals and technology converge, individuals converge into networks, societies converge, and humanity finally becomes unified. Environmental degradation, poverty, disease, cultural misunderstanding, war, etc. can all be solved through NBIC convergence. The NBIC world is akin to a hall of mirrors with NBIC convergence at the center: though stretched, contorted, and deformed, every reflection refers back to the principle of NBIC. It is precisely this that makes the extrapolated future credible. 


\section{SF in NST: Bridging too many Gaps}

The reasons why the device of the novum fails to generate a propitious context for the consideration of the ethical and social implications of NST are the very same reasons that explain its success and centrality as a narrative device in the literary genre of SF. In the later, its function is the construction of a coherent and plausible world that is separated from our own world in time and/or space. This is achieved by making the novum the crucible on which all aspects of the extrapolated world are forged. It functions through a viral logic by replicating itself in all the principal phenomenological domains of the chronotope. The price of plausibility and coherence is unidimensionality -i.e. organizing the structure of the world around one principle. ${ }^{29}$ This constructed world in turn provides the ontological stage in which the characters are embedded and the plot unfolds. However, when this same narrative technique is used in NST discourse to extrapolate from current technoscientific abilities to the future, a number of problematic effects are produced.

First, SF literature typically incorporates a historical account, or future history, that explains how the fictional world has come about. It normally contains the period before, during, and after the novum. If the narrated world is to be credible, the relationship between the three periods must be one of inevitability. This sense of historical necessity is also reproduced, as I have shown above, when the novum structures NST discourse. Thus, as a result of how their respective nova have generated the diachronic and synchronic dimensions of their sublime chronotopes, Drexler and Roco and Bainbridge's accounts create a sense of inevitability. However, if the inevitability of these processes are accepted, then there is logically and discursively a rather limited role for ethical reflection or analysis of social implications.

Second, to the extent that the novum used to extrapolate a future world is a technoscientific innovation, as is the case in NST discourse, then the extrapolation will take on a technological determinist logic. Technological determinism explains social, cultural, political, and economic change in terms of technoscientific development. However, this logic is a poor operationalization of the dynamics between technoscience and society. The framing of technoscience as the explanatory cause of social phenomena fails to register the complex processes that embed technoscientific practice in specific social, cultural, political, and economic relations. Indeed, as the body of scholarship developing around the social studies of science reveals, technoscience is a social achievement dependent on, for instance, economic rationalities, contests for legitimacy and authority, micro-interactions in the laboratory, social organization, and the development of social networks (Gieryn 1999, Latour \& Woolgar 1986). Thus, technoscientific practice relies on the simultaneous production and/or mobilization of social, economic, political, and cultural 
conditions through which it is invested with legitimacy and effectivity (Latour 1986, Turnbull 2000). The specific ways in which these social processes are negotiated will open up certain developmental pathways while closing off others. It is for this reason that Latour claims that technologies "far from primarily fulfilling a purpose [...] start by exploring heterogeneous universes that nothing, up to that point, could have foreseen and behind which trail new functions" (Latour 2002, p. 250). The extrapolative structure of the novum erases the contingencies inherent in technoscientific development by projecting it along a linear developmental path that will most certainly be frustrated. As Brown (2003, p. 4) argues, "In the short term we tend to completely overestimate the practical capabilities of technologies. In the longerterm we tend to get it wrong altogether, with technologies occasionally taking us completely by surprise". This becomes particularly problematic when these developmental paths are invested, as they are within a technological determinist logic made possible by the novum, with the ability to resolve all manner of social, cultural, and political problems. Potential non-technological solutions become marginalized and are not pursued.

However, the most fundamental shortcoming of deploying the novum as a device for framing discussions on the ethical and social implications of NST is that the novum bridges far too many gaps! $!^{30}$ It not only bridges the technical gap, but also the social and ethical gaps by generating a (fictional) future social world which contains beneficent social implications with only minor ethical complications. As we saw above, the technologies extrapolated from molecular assemblers and NBIC convergence promise a future of prosperity, peace, and physical well-being. Framed in this way, not to promote these technologies and their alleged beneficent social impacts becomes politically negligent if not utterly unethical. However, this momentum towards action obscures the fact that the credibility of the beneficent social implications and the lack of serious ethical conundrums are secured by the narrative structure of the novum, not through a critical analysis of social outcomes or serious ethical or normative discussion.

Moreover, the novum also assigns the social sciences and humanities the function of analyzing and contributing to the management of the social processes necessary to arrive at the proposed future. In this way, they are divested of their potential critical role. For instance, social scientists are asked to analyze public opinion with a view to overcoming public resistance through the effective communication of nano-benefits and promises: i.e. by including the public in the political economy of desire and hope generated by the novum. ${ }^{31}$ They are also asked to aid nano-development by analyzing the mechanisms and procedures which will streamline processes of nanoinnovation..$^{32}$ In all these contexts, social scientists and humanities scholars are not invited to test the assumptions that underpin the social future gener- 
ated by the novum. Thus, it becomes difficult to envision how a truly critical space is to develop.

Moreover, the totalizing utopian vision produced by the novum invites similarly generated counter-visions. The latter deploy the structure of the novum much as do the former; they differ only in the malevolent logic with which the narrative is invested..$^{33}$ Consequently, it is extremely likely that the production of dystopian NST futures may arise not so much from technophobia, fear-mongering, or inadequate knowledge but from the difficulty of criticizing the seemingly impenetrable utopian futures projected through the novum. In this context, the most effective critical maneuver is to insert a dystopian virus into a pro-NST program and use its novum to assemble a dystopian future.

An understanding of this phenomenon is particularly important because it is the dystopian novum that has drawn the attention of popular culture and has, as argued by Marshall (2004), contributed as much to the development of NST as has its utopian counterpart. However, for many of the reasons listed above, in the context of the utopian novum, the dystopian register fails as a constructive critique of the social and ethical consequences at stake in NST. ${ }^{34}$

\section{Conclusion}

In this paper, I have argued that the relation between SF narrative elements and NST is not external but internal. This is due to NST's radical future orientation, which opens up a gap between what is technoscientifically possible today and its inflated promises for the future. I have argued that this gap is bridged by linking the dominant metaphor in NST discourse - the nanotechnoscientist as the master builder - to SF narrative techniques used to build future or parallel worlds. I have examined these techniques in detail in two NST texts: Drexler's Engines of Creation and Roco and Bainbridge's text on NBIC convergence. I have tried to show how narrative techniques are used in order to extrapolate credible and plausible futures through a synchronic and diachronic re-ontologization of the world.

I have not been concerned with exploring whether this type of narrative process is incompatible with scientific practice. I have, however, identified a number of obstacles that it poses for a critical discussion of ethical and social implications. First, both the sense of inevitability and technological determinism, associated with the novum, tend to erode the necessity of analyses of ethical and social implications. Second, I have drawn attention to the fact that the novum does more than merely bridge the technical gap; it also bridges the ethical gap by narrating a desirable fictional social world organized around the extrapolated technology. This contains the moral imperative to realize the 
extrapolated society while simultaneously cloaking the extent to which the plausibility of the extrapolated society is a function of the narrative device of the novum. In this context, the role for the humanities and the social sciences is to facilitate the development of the technology rather than to critically engage with it. Finally, I have suggested that the radical immunity to critique that is constructed through the novum creates an ideal medium for dystopian counter visions that in turn display many of the same shortcomings in their apocalyptic rendering of NST. I would argue that an understanding of these discursive tendencies must be borne in mind in the attempt to open up a space for a more open and critical analysis of the ethical and social implications of NST.

However, in highlighting how SF narrative elements in NST discourse fail to facilitate effective critical engagement, I am not arguing that SF as a literary genre is not a suitable vehicle for critical reflection on technoscientific developments. ${ }^{35} \mathrm{It}$ is necessary to be clear about the fact that the existence of SF narrative elements in NST discourse does not make the latter a work of literary SF. What is more, SF as a literary genre is, in fact, better at opening up a space for critical reflection than is the NST discourse described and analyzed in this paper. In other words, ironically literary SF succeeds where NST discourse fails. This is because, as SF writer and critic Samuel R. Delaney argues, "Science fiction is not about the future; it uses the future as a narrative convention to present significant distortions of the present" (1984, p. 47). Similarly, Frederick Jameson (1982) argues that these distortions serve to defamiliarize the present and open up the exploration of alternative social, cultural, and political arrangements. The plausibility of the extrapolated 'future' in SF need only be sufficient to stage the exploration of scientific, political, social, and cultural questions in dramatic form. As a result, SF is

less concerned with the 'objective' factors that give rise to a specific future, less concerned with forecasting or describing possible future societies, than

$[\ldots]$ with presenting a specific future and discovering what it means to act in specific ways in terms of the belief that those ways of acting are necessary for accepting, rejecting or doubting the principles upon which a particular future social order rests. [Elkins 1979, p. 24]

Thus, the 'future' in SF is only a dramatic device for exploring the present. In contrast, NST discourse confuses the effect of the 'future' produced by the novum and its related narrative strategies for the future itself. It confuses the suspended disbelief that is evoked by a world organized around a single principle as a vehicle for a dramatic enactment with foresight. Whereas in SF the extrapolated future is a stepping-stone for critical reflection, in NST discourse the extrapolated future is the endpoint of the reflection.

Given the range of techniques, tools, instruments, machines, algorithms, materials, hardware, processes, projects, disciplines, actors, economic inter- 
ests, and governance agendas that are included under the rubric of NST, it is unlikely that the fields of NST will all develop in unison. More likely than not they will produce varied ethical, legal, and social implications that will have to be monitored and analyzed as they unfold in different social, cultural, political, and economic contexts. An ethical lag is only a problem if we lack the social and political institutions to restrain technoscience when we deem it necessary. A necessary corrective to the unrealistic task of trying to understand the ethical and social implications of NST as if they were one process is to ask ourselves: Does it make sense to group all our macro-technologies in the same way? Moreover, if it is true that the extrapolated future made possible by SF narrative speaks more to the present than the future, we might ask ourselves what are the ethical and social implications of an organization of technoscientific activity that needs to claim such clairvoyance and promise so much to merely function?

\section{Notes}

1 I am grateful to the two anonymous referees for their lucid and extremely helpful comments. I would like to thank Telsing Andrews who tirelessly read and commented on a number of incarnations of this paper as well Peter Yeadon for his helpful comments and Bryn Williams-Jones who read and commented on an earlier version. This paper was first delivered at the 2004 Canadian Sociological and Anthropological Association session titled, 'On the Social and Ethical Impacts of Nanotechnology', in Winnipeg. I want to thank the other two participants in the session, Chris MacDonald and Crystal Wallin, as well as the members of the audience. However, I would especially like to thank Michael Mehta for organizing the session, acting as a discussant and for the supportive environment he created.

2 There is a simple economic logic related to my use of the acronym NST in lieu of the expression 'Nanoscience and Technology': the acronym is shorter than the phrase both the acronym and the referent are borrowed from Wood et al. (2003, p. 5). In addition, there are also two theoretical points to be made. As Wood et al. note, the use of NST to refer to "a new branch of science" alerts us to the fact that there is a concerted effort to bring together disparate scientific practices or to locate one's existing research program under a fashionable and money worthy umbrella (ibid.). This should not be taken to mean, however, that there is consensus on the meaning of NST itself. As I note below in the body of the text, controversy remains. Second, by grouping science and technology together, the term problematizes traditional models of linear knowledge transfer from state supported research in fundamental science to technological applications. On the relationship between nanoscience and nanotechnology, see Wood et al. 2003, pp. 5-17, and Fogelberg 2003. For a broader analysis of the relationship between science and technology, see Nowotny et al. 2001.

3 Nowotny et al. (2001, p. 183) argue that science has "moved centre-stage in what we call the agora - the space in which market and politics meet and mingle, where the articulation of private emotions and meanings encounter the formation of public opinion and political consensus”. See also Ravetz 1999. 
4 I would like to make clear that by no means does my focus on narrative features and discursive strategies, in this paper, exhaust NST as a social, cultural, economic, and political phenomena. A more comprehensive treatment of NST, which is beyond the scope of this paper, would include dimensions such as cultural practices in the laboratory, the policing of disciplinary boundaries, funding sources, national policy cultures, etc.

5 Roco is senior advisor to the NSF and chair of the Nanoscale Science, and Engineering and Technology Subcommittee (NSEC) of the National Science and Technology Committee (NSTC). He was one of the key architects of the launch and is current director of the multiagency NNI and remains a tireless promoter of NST. Bainbridge is Deputy Division Director at the Directorate for Computer and Information Science Engineering (CISE) whose program responsibilities include nanoscale science and engineering.

6 Theoretically and methodologically, my analysis is framed by a conception of scientific knowledge that locates scientific knowledge production in discursive formations that incorporate both discursive and non-discursive elements (Foucault 1992, López 2004) and that require the mobilization of a variety of social and cultural resources (Callon 1986, Gieryn 1999). In this context, discourse is not understood as the distorted, or more or less accurate, representation of reality: discourse is one of the social forces that contribute to the constitution of reality. The two texts chosen for analysis have been selected not because they constitute a sample or a representation of the entire NST field, but because they are both key attempts to mobilize a variety of social actors through their broad vision of the NST field, and they are strategically well placed to do so: the Drexler text because it inaugurated the field and the NBIC text because of its proximity to the NNI, which has been central to the development of a NST program in the US. They are, to use Callon's term, two good examples of “translations” (Callon 1986).

7 Later, I discuss Drexler's vision of nanotechnology in some detail; for the moment, it is enough to say that he foresees the development of self-replicating molecular machines that will make possible the production of bulk material from the nano to the macro scale. This vision is held and promoted by the Foresight Institute (www.foresight.org) that Drexler co-founded.

8 See Milburn 2002, for further examples of the science fiction/fact opposition.

9 See Hamilton 2003, for an excellent discussion of these dynamics in the context of biotechnology.

10 Hamilton (2003) uses the Latourian terminology to describe biotechnology, but it is even more applicable to NST.

11 See Wood et al. 2003 for a useful overview. On the challenges of interdisciplinarity in current integrative attempts in NST, see Schummer 2004.

12 The newness must be approached with care because of the diversity of the field. As Wood et al. (2003, p. 10) argue with respect to material sciences, "Many advances that are being ascribed to nanotechnology could equally be regarded as an incremental development of existing technologies"; see also Atkins 2002.

13 These new behaviors and properties are initially expected to broadly impact, amongst others, the fields of materials science, electronic and optoelectronics, and the biomedical sciences (Wood et al. 2003, pp. 10-16).

14 The role of metaphors in the organization of knowledge domains has been recognised by philosophers, historians, and sociologists of science for some time. See López 2003, chap. 1, for an overview. 
15 In focusing on this metaphor, I am not arguing that it is an 'accurate' representation of the field, rather I am registering its contemporary ubiquity and prominence. It is important also to note that the metaphor not only attempts to 'represent' heuristically the work of NST but also its social function. A comparison with competing and less successful competitors would be highly instructive but cannot be undertaken within the context of this paper.

16 See Roco \& Bainbridge 2001, 2003.

17 For the role of hype in the promotion of "revolutionary" technologies see Brown 2003 and William-Jones \& Corrigan 2003.

18 On SF thinking, see Csicsery-Ronay 1991 and Gerlach \& Hamilton 2000.

19 Ralph Merkle, closely associated with the Foresight Institute, however, did testify in the congressional hearings that lead to the launch of the NNI in 2001 (Milburn 2002, p. 277).

20 See Smalley 2001 for his initial critique. For recent exchanges between the two, see Drexler \& Smalley 2003.

21 In a different context, Milburn 2002 very skillfully demonstrates that the boundary between mainstream and periphery in NST discourse is more porous than is often supposed.

22 Recently, Drexler has denied the need for self-replication (Phoenix \& Drexler 2004).

23 Csicsery-Ronay points to related concepts in SF author and critic Samuel R. Delany's account of "paraspaces” (1995, p. 168) and literary critic Brian McHale's "narrative zones" (1987, p. 5).

24 This of course corresponds to the SF narrative device of the future history which provides a 'logical' historical explanation for the movement from the author's real time to the future (Csicsery-Ronay 1996, p. 386); see also James 1996, pp. 54-94.

25 It could indeed be argued that NST, properly speaking, does not exist outside of this type of national initiative.

26 See for instance Roco 2004.

27 In a logic which can only be understood as oxymoronic, elsewhere Roco argues that reductionism characterizes those disciplines that refuse the holistic reductionism of NBIC (Roco 2003b, p. 93). See Csicsery-Ronay 1996, for the role of the oxymoron in SF.

28 See Kay 2000 and Thacker 2004, for accounts of the development of DNA as an informational entity.

29 The unidimensionality refers to the principles of construction of the chronotope but not SF literature itself.

30 Mnyusiwalla et al. (2003) draw attention to the gap between NST and ethics.

31 See Bainbridge 2002 and Thompson 2001.

32 See Carroll 2001 and Crow \& Sarewitz 2001.

33 See for instance Joy 2000 and Drexler's own account of Grey Goo (Drexler 1990, pp. 171-190).

34 I am grateful to one referee who drew these very important points to my attention.

35 For accounts of the critical potential associated with SF, see Csicsery-Ronay 1991, Delany 1984, Elkins 1979, Gerlach \& Hamilton 2000, Jameson 1982, Milburn 2002, Thacker 2000, and Suvin 1979. 


\section{References}

Albus, J.S.: 2003, 'Engineering of Mind for Enhancing Human Productivity', in: M.C. Roco, W.S. Bainbridge (eds.), Converging Technologies for Improving Human Performance, Kluwer, Dordrecht, pp. 281-293.

Albus, J.S.; Bainbridge, W.S.; Banfield, M.; Dastoor, C.A.; Murray, K.; Carley,M.; Hirshbein, T.; Masciangioli, T.; Miller, R.; Norwood, R.; Price, P.; Rubin, J.; Sargent,G.; Wallace, W.A.: 2003, 'Enhancing Group and Societal Outcomes: Theme D Summary', in M.C. Roco, W.S. Bainbridge (eds.), Converging Technologies for Improving Human Performance, Kluwer, Dordrecht, pp. 275-277.

Atkins, P.: 2003 'The Future of Matter', in: J. Brockman (ed.), The Next Fifty Years: Science in the First Half of the Twenty-First Century, Vintage Books, New York, pp.194-205.

Bainbridge, W.S.: 2002, 'Public Attitudes Toward Nanotechnology', Journal of Nanoparticle Research, 4, 561-570.

Brown, N.: 2003, 'Hope Against Hype - Accountability in Biopasts, Presents and Futures', Science Studies, 16(2), 3-21.

Callon, M.: 1986, 'Some Elements of a Sociology of Translation', in J. Law (ed.), Power, Action and Belief: A New Sociology of Knowledge?, Routledge, London, pp. 196-223.

Carroll, J.S.: 2001, 'Social Science Research Methods for Assessing Societal Implications of Nanotechnology', in: M.C. Roco, W.S. Bainbridge (eds.), Societal Implications of Nanoscience and Nanotechnology, National Science Foundation, pp. 188-192.

Crow, M. \& Sarewitz, D.: 2001, 'Nanotechnology and Societal Transformation', in: M.C. Roco, W.S. Bainbridge (eds.), Societal Implications of Nanoscience and Nanotechnology, National Science Foundation, pp. 45-54.

Csicsery-Ronay, I. Jr.: 1996, 'The Seven Beauties of Science Fiction', Science Fiction Studies, 23, 385-392.

Csicsery-Ronay, I. Jr.: 1991, 'The SF of Theory: Baudrillard and Haraway', Science Fiction Studies, 18, 387-404.

Delaney, S.R.: 1984, Starboard Wine: More Notes on the Language of Science Fiction, Dragon Press, New York.

Delaney, S.R.: 1994, Silent Interviews, Univ. Press of New England, Hanover, NH.

Drexler, E.: 1990 [1986], Engines of Creation, Anchor Books, New York.

Drexler, E.; Smalley, R.E.: 2003, 'Point-Counterpoint: Nanotechnology', Chemical and Engineering Neres, 81(48), 37-42.

Elkins, C.: 1979, 'Science Fiction versus Futurology: Dramatic Versus Rational Models', Science Fiction Studies, 6, 20-31.

Evans, J.H.: 2002, Playing God? Human Genetic Engineering and the Rationalization of Public Bioethical Debate, Chicago University Press, Chicago.

Fogelberg, H.: 2003, "Science" and "Technology" as Knowledge Cultures', in: H. Fogelberg, H. Glimell, Bringing Visibility to the Invisible: Towards a Social Understanding of Nanotechnology, Göteborg University, Göteborg, pp. 77-85.

Fogelberg, H.; Glimell, H.: 2003, Bringing Visibility to the Invisible: Towards a Social Understanding of Nanotechnology, Göteborg University, Göteborg.

Foucault, M.: 1992, The Archaeology of Knowledge, Routledge, London.

Gieryn, T.: 1999, Cultural Boundaries of Science, Univ. of Chicago Press, Chicago.

Graham, P.: 2002, 'Hypercapitalism: Language, New Media and Social Perceptions of Value', Discourse and Society, 13(2), 227-249.

Gerlach, N.; Hamilton, S.: 2000, 'Telling the Future, Managing the Present: Business Restructuring Literature as SF', Science Fiction Studies, 27, 461-477. 
Hamilton, S.: 2003, 'Biotechnology, SF and the Media', Science Fiction Studies, 30, 267-282.

Haraway, D.J.: 1997, Modest Witness@Second Millenium.FemaleMan(c) Meets OncoMouse ${ }^{\text {TM }}$, Routledge, London and New York.

Huijer, M.: 2003, 'Reconsidering Democracy: History of the Human Genome Project', Science Communication, 24(4), 479-502.

James, E.: 1994, Science Fiction in the 20 th Century, Oxford University Press, Oxford.

Jameson, F.: 1982, 'Progress Versus Utopia; or, Can We Imagine the Future', Science Fiction Studies, 9, 147-158.

Johnson, P.C.: 2003, 'Implications of the Continuum of Bioinformatics', in: M.C. Roco; W.S. Bainbridge (eds.), Converging Technologies for Improving Human Performance, Kluwer, Dordrecht, pp. 207-212.

Joy, B.: 2000, 'Why the Future Doesn't Need us', Wired, 8 [www.wired.com/wired/archive/8.04/joy.html].

Kay, L.: 2000, Who Wrote the Book of Life? A History of the Genetic Code, Stanford University Press, Stanford.

Landon, B.: 2004, 'Less is More: Much Less is Much More: The Insistent Allure of Nanotechnology Narratives in Science Fiction', in: K. Hayles (ed.), NanoCulture, Intellect Books, Bristol, pp. 59-78.

Latour, B.: 1986, 'Visualisation and Cognition: Thinking With Eyes and Hands', Knowledge and Society, 6, 1-40.

Latour, B.: 2002, 'Morality and Technology: The End of the Means', Theory, Culture and Society, 19(5/6), 247-260.

Latour, B. \& Woolgar, S.: 1986, Laboratory Life: The Social Construction of Scientific Facts, $2^{\text {nd }}$ edn., Princeton University Press, Princeton.

López, J.: 2003, Society and Its Metaphors: Language Social Theory and Social Structure, Continuum, New York and London.

López, J.: 2004, 'How Sociology Can Save Bioethics...Maybe', Sociology of Health and Illness, 26(7), 1-22.

McCain, L.: 2002, 'Informing Technology Policy Decisions: the US Human Genome Project's Ethical, Legal and Social Implications Programs as a Critical Case', Technology and Society, 24, 111-132.

McHale, B.: 1987, Postmodern Fiction, Methuen, New York \& London.

Marshall, K.: 2004, 'Atomizing Risk Technology', in: K. Hayles (ed.), NanoCulture, Intellect Books, Bristol, pp. 79-102.

Miksanek, T.: 2001, 'Microscopic Doctors and Molecular Black Bag: Science Fiction's Prescription for Nanotechnology and Medicine', Literature and Medicine, $21(1), 55-70$.

Milburn, C.: 2002 'Nanotechnology in the Age of Posthuman Engineering: Science Fiction as Science', Configurations, 10, 261-295.

Mnyusiwalla, A.; Daar, A.S.; Singer, P.A.: 2003, “Mind the Gap": Science and Ethics in Nanotechnology, Nanotechnology, 14, R9-R13.

Nowotny, H.; Scott, P.; Gibbons, M.: 2001, Re-thinking Science, Polity, Cambridge.

NSTC (National Science and Technology Council): 1999, Nanotechnology: Shaping the World Atom by Atom [www.wtec.org/loyola/nano/IWGN.Public.Brochure/ IWGN.Nanotechnology.Brochure.pdf, accessed: 15 Nov. 2003].

Phoenix, C.; Drexler, E.: 2004, 'Safe Exponential Manufacturing', Nanotechnology, 15, 869-872.

Ratner, M.; Ratner, D.: 2003, Nanotechnology, Prentice Hall, New Jersey.

Ravetz, J.: 1999, 'What is Post-normal Science?', Futures, 31, 647-653.

Roco, M.C.: 2003a, 'Broader Societal Issues of Nanotechnology', Journal of Nanoparticle Research, 5, 181-189. 
Roco, M.C.: 2003b, 'Coherence and Divergence in Megatrends in Science and Engineering', in: M.C. Roco, W.S. Bainbridge (eds.), Converging Technologies for Improving Human Performance, Kluwer, Dordrecht, pp. 79-96.

Roco, M.C.: 2003c, 'Fundamentally New Manufacturing Processes and Products', in: Roco, M.C. \& Bainbridge, W.S., (eds.), Converging Technologies for Improving Human Performance, Kluwer, Dordrecht, pp. 300-302.

Roco, M.C.: 2004, 'The Emergence and Policy Implications of Converging Technologies' [www.nsf.gov/home/crssprgm/nano/nbic_roco_04_0422_@aaas_57sl.pdf, accessed May 2004].

Roco, M.C. \& Bainbridge, W.S., (eds.): 2001, Societal Implications of Nanoscience and Nanotechnology, National Science Foundation [online: www.wtec.org/loyola/ nano/societalimpact/nanosi.pdf, accessed: 15 November 2003].

Roco, M.C. \& Bainbridge, W.S., (eds.): 2003, Converging Technologies for Improving Human Performance: Nanotechnology, Biotechnology, Information Technology and Cognitive Science, Kluwer, Dordrecht.

Rothman, B.K.: 1998, Genetic Maps and Human Imagination, W.W. Norton, New York \& London,

Schummer, J.: 2004, 'Interdisciplinary Issues in Nanoscale Research', in: D. Baird, A. Nordmann, J. Schummer (eds.), Discovering the Nanoscale, IOS Press, Amsterdam, pp. 9-20.

Shultz, W.: 2000, 'Nanotechnology: The Next Big Thing', Chemical and Engineering Nerws, 78(18), 41-47.

Smalley, R.E.: 2001, 'Of Chemistry, Love and Nanobots', Scientific American, 285(3), September, 76-77.

Stix, G.: 1996, 'Trends in Nanotechnology: Waiting for Breakthroughs', Scientific American, 274(4), 94-99.

Suvin, D.: 1979, Metamorphoses of Science Fiction, Yale University Press, New Haven.

Thacker, E.: 2000, 'SF, Technoscience, Net.art: The Politics of Extrapolation (science fiction)', Art Journal, 59(3), 64-73.

Thacker, E.: 2004, Biomedia, University of Minnesota Press, Minneapolis.

Theis, T.: 2001, 'Information Technology Based on a Mature Nanotechnology', in: M.C. Roco, W.S. Bainbridge (eds.), Societal Implications of Nanoscience and Nanotechnology, National Science Foundation, pp. 60-67.

Thompson, P.B.: 2001, 'Social Acceptance of Nanotechnology', in: M.C. Roco, W.S. Bainbridge (eds.), Societal Implications of Nanoscience and Nanotechnology, online: National Science Foundation, pp. 198-202.

Turnbull, D.: 2000, Masons, Tricksters and Cartographers, Harwood, Amsterdam.

William-Jones, B.; Corrigan, O.: 2003, 'Rhetoric and Hype: Where's the Ethics in Pharmacogenomics?', American Journal of Pharmacogenomics, 3(6), 375-383.

Wood, S., Jones, R.; Geldart, A.: 2003, The Social and Economic Challenges of Nanotechnology, UK Economic and Social Research Council [www.esrc.ac.uk/ esrccontent/DownloadDocs/Nanotechnology.pdf, accessed: 3 Feb. 2004].

José López:

Department of Sociology, University of Ottawa, Ottawa, K1N6N5,Canada; jlopez@uottawa.ca 